\title{
A autobiografia educativa na FEUSP: desafios para a formação de pesquisadores em início de carreira
}

\author{
An educational autobiography at FEUSP: challenges for the \\ professional development of researchers at the start of their
}

Nilce da Silva

Profa. Dra. da Faculdade de Educação da Universidade de São Paulo nilce@usp.br

Ivan da Silva Poli

Mestrando da Faculdade de Educação da Universidade de São Paulo ivan.poli@usp.br

\begin{abstract}
Resumo
Este artigo consiste em análise do relato autobiográfico de um estudante do Mestrado da Faculdade de Educação da Universidade de São Paulo (FEUSP), produzido no âmbito da disciplina "Professor universitário: vida, perfil e formação", no segundo semestre de 2011. No texto, procuramos teorizar sobre a validade epistemológica do relato autobiográfico como metodologia para a pesquisa em educação e tecer considerações acerca da formação de professores e pesquisadores. Por fim, apontamos alguns caminhos para tanto.
\end{abstract}

Palavras-chave: Formação de Pesquisadores. Formação de Professores. Metodologia de Pesquisa. Relato Autobiográfico.

\footnotetext{
Abstract

This article consists of an analysis of the autobiographical account of master's students at the School of Education of the University of São Paulo (FEUSP), produced in the Becoming a University Professor course: life, profile and professional development in the second semester of 2011. In the article, we will theorize about the epistemological validity of autobiographical account as a methodological tool for research in education and make considerations about the training of teachers and researchers, and finally point out some ways to do both.

Key words: Autobiographical Narrative. Research Methodology. Researcher's Training. Teacher's Training.
} 


\section{Introdução}

Este artigo constitui uma reflexão acerca do relato autobiográfico do mestrando Ivan da Silva Poli, do Programa de Pós- Graduação da Faculdade de Educação da Universidade de São Paulo (FEUSP), produzido no âmbito da disciplina "Professor universitário: vida, perfil e formação", no segundo semestre de 2011. Com tal reflexão, pretende-se identificar as características do pesquisador em início de carreira, sob o entendimento de que se trata de uma categoria profissional cuja formação graduada não se apresenta institucionalizada e, por isso, não contempla a aquisição de competências técnicas específicas à função que vão desempenhar. Além disso, a análise aqui proposta pode facilitar a definição dos saberes e dos modelos de formação mais necessários e adequados para o exercício da função de professor-pesquisador, nos moldes em que outros estudiosos têm teorizado. (Cf. NÓVOA; FINGER, 2010)

Tal relato contém as experiências vivenciadas pelo mestrando em instituições educacionais e religiosas no Oriente, mais especificamente na Índia, na Fundação Ramakrishna. Traça reflexões acerca de sua prática profissional, não só como professor, mas também como pesquisador em início de carreira. Consideramos que tal experiência vivenciada pelo estudante apresenta desafios para a autobiografia educativa como metodologia de pesquisa.

Ao longo do relato de Ivan conseguimos perceber que ele "conta" a sua história, rememorando o instinto autobiográfico do ser humano: a narração. Assim, o estudante narra acontecimentos; procura explicar seu passado e seu presente; projeta seu futuro e justifica suas ações, exercendo sobre o outro, por meio da palavra, um determinado efeito de convencimento. (MACIEL, 2004)

O artigo segue organizado nas seguintes partes: 1- aspectos gerais da disciplina "Professor universitário: vida, perfil e formação"; 2 - passagens marcantes do relato autobiográfico produzido, e 3- reflexões acerca dos desafios da autobiografia e da importância da disciplina e da respectiva metodologia de pesquisa da qual ela trata.

\section{Parte I: Disciplina "Professor universitário: vida, perfil e formação"}

Esta disciplina é oferecida no Programa de Pós-Graduação em Educação da FE-USP pela professora Helena C. Chamlian e tem como objetivos: oferecer aos 
alunos de pós-graduação e docentes da Universidade de São Paulo elementos para o estudo teórico da profissão docente; proporcionar momentos de reflexão sobre sua profissão e formação por meio das "biografias educativas", autobiografias, ou "pesquisa/formação" de professores; trazer subsídios para que o professor encontre alternativas para lidar com a realidade pedagógica do cotidiano de sala de aula, a partir da compreensão de seus eixos de formação; favorecer a compreensão dos elementos presentes no processo de aprendizagem do grupo estudado, pela análise e reflexão das autobiografias produzidas, e permitir que o professor em processo de formação enriqueça sua compreensão a respeito de seus alunos, eles próprios adultos

Para atingir tais objetivos, a disciplina contempla o seguinte conteúdo: a evolução da profissão docente: questões teóricas; as histórias de vida e seu papel na formação do professor; histórias de vida, biografias e autobiografias - alguns relatos extraídos da literatura; a produção de autobiografias escolares e análise e reflexão sobre a produção individual e coletiva.

Essa disciplina proporcionou aos seus alunos a realização de ateliers para a construção de autobiografias, uma delas a do mestrando Ivan Poli, explorando a sugestão de Nóvoa (1995, p. 25): "Urge por isso (re) encontrar espaços de interação entre as dimensões pessoais e profissionais, permitindo aos professores apropriarse dos seus processos de formação e dar-lhes um sentido no quadro das suas histórias de vida ${ }^{1}$.

\section{Parte II: Índia, Vedanta e educação: a experiência Ramakrishna}

O relato autobiográfico de Ivan se intitula: O Filho das águas pelas Indias e Orientes e resultou no livro Índia, Vedanta e educação, a experiência Ramakrishna (2012) ${ }^{2}$. Esse livro é composto pelos acontecimentos mais significativos da sua vida, destacando-se sua experiência na Índia, na Fundação Ramakrishna, e seu envolvimento com Vaishali, sua noiva indiana à época, como momento-charneira ${ }^{3}$. Nas palavras do depoimento de Poli (2012, p. 5):

A partir desta experiência resolvi escrever o livro acima, contudo não via sentido em iniciar o tema sem utilizar ao menos uma parte do meu relato ampliado (a maior parte) como capítulo de apresentação. 
O livro inicia assim com o relato ampliado. Na segunda parte da obra, introduzo o tema da filosofia Vedantina, expondo esta filosofia no contexto de todas as filosofias provenientes dos Vedas ou não na Índia, no que ela se relaciona com minha história de vida e trajetória e cito os filósofos: Swami Vivekananda e Sri Ramakrishna. Na terceira parte, transcrevo meu relatório de iniciação científica, que foi uma pesquisa em que relacionei os elementos da Filosofia Vedantina com a Psicanálise de Winnicott, além de tratar de forma central das relações mestre-discípulo na Índia Vedantina e fazer uma transposição para a realidade ocidental inspirado em Georges Gusdorf. No final, falo sobre a experiência Ramakrishna em si mesma, criticando o determinismo sociológico de autores como Pierre Bourdieu e Louis Althusser e as possibilidades de combater a reprodução social promovida pela instituição escolar através da afirmação cultural e identitária dos indivíduos, conforme observado na Fundação Ramakrishna e no processo de formação que ocorreu com o próprio autor que é descrito no relato autobiográfico.

Por este breve trecho, verifica-se que o autor não teve uma vida reduzida a aspectos técnicos nem acadêmicos, muito menos a aspectos racionais. Ele é visto como uma 'pessoa inteira'. Constatamos, por meio do seu relato, as opções contantes que cruzam a maneira de ser de Ivan com o modo de atuar na escola, e deste modo temos desvendada a sua maneira de ser e a clara percepção de que existe, portanto, uma forte articulação entre o pessoal e o profissional, o que nos leva a concordar com Finger (1984, p. 84): “o método biográfico se justifica pelo fato de valorizar uma compreensão que se desenrola no interior da pessoa, sobretudo em relação a vivências e a experiências que tiveram lugar no decurso da sua história de vida".

A seguir, vejamos algumas passagens signitivas do material coletado no âmbito da disciplina da FEUSP e que constituem, do nosso ponto de vista, 'momentos- charneira' da vida de Ivan.

\section{Passagens marcantes}

No âmbito da autobiografia educativa, passagens marcantes são chamadas de 'momentos-charneira', nos quais 
o sujeito confronta-se consigo mesmo. A descontinuidade que vive impõe-lhe transformações mais ou menos profundas e amplas. Surgem-lhe perdas e ganhos e, nas nossas interações, interrogamos o que o sujeito fez consigo próprio ou o que de si mesmo para se adaptar à mudança, evitá-la ou repetir-se na mudança. (JOSSO, 1988, p. 44)

O relato começa por uma volta às origens em que o autobiografado, para buscá-las, percorre diferentes continentes: "Sou descendente de 13 povos diferentes e em minhas andanças pelo mundo pude conhecer bastante sobre eles e estas origens" (página). Este trecho corrobora as palavras de Josso (2002, p. 8), em que este autor afima que "(...) a consciência nasce quando interpretamos um objeto com o nosso sentido autobiográfico, a nossa identidade e a nossa capacidade de anteciparmos o que há de vir".

Neste início, percebemos o processo de busca de Ivan pela construção da sua identidade, tendo como o "Outro" o branco europeu. Ele lembra, dentre outros compositores, Caetano Veloso quando este diz que "[...] me fizeram amar cada vez mais minha Nação que não pode estar desvinculada de minha origem familiar, a quem aprendeu que mais vale ser brasileiro que uma cópia mal feita de europeus". (POLI, 2012, p. 13)

Na sua infância, a adoção da sua irmã Luciana foi um fato marcante. Interessante notar aqui que Ivan explica este acontecimento por meio de referenciais religiosos que marcam todo o sentido atribuído a sua vida.

Ao longo de todo o seu relato, Ivan aponta o gosto que tem pelas viagens. São inúmeras as referências que ele faz a este gosto que começou quando sua família muda de São Paulo para Fortaleza: as viagens feitas com o pai de caminhão por todo o Brasil e ainda o encantamento que tinha ao olhar o globo iluminado quando ainda era um menino. Aliado ao gosto pelo estar em trânsito, podemos observar a paixão pelo saber nutrida por ele:

[Eu] Era um excelente aluno e sempre amei os estudos, nunca deixando de brincar com meu globo iluminado sonhando em conhecer os lugares e falar as línguas das latitudes e longitudes que iluminava em meu Globo ou dos mapas de supostos países e povos que inventava a partir dos mapas que ganhava, preferia ganhar mapas que brinquedos idiotas dos programas infantis 
imbecís de TV , por isso adorava jogar Banco Imobiliário ou WAR II , por serem jogos que se referiam a lugares ou mapas, ou então preferia adiantar alguns meses sozinho a resolução dos exercícios de matemática dos livros didáticos para poder me preparar melhor para nossas viagens de final de ano pelas praias do Nordeste. Adorava Geografia e Matemática e no Ceará todos meus colegas me chamavam de filho do paulista. (POLI, 2012, p. 20)

Com relação à vida escolar revisitada, Ivan nos fala de Gina, professora severa, a melhor, "que não fazia questão de rezar o pai nosso quando sua aula era a primeira do dia" (POLI, 2012, p. 18). Relata também sua relação conflituosa com uma das mulheres que trabalhou como doméstica na casa de seus pais, mesmo sabendo falar francês e quase diplomada, e que resolveu lhe ensinar a norma culta: "Mas não me esqueço dos beliscões e tapas que levava da Norma Culta quando errava a leitura de um texto na qual ela me auxiliava». Esta senhora se chamava, coincidentemente, Norma” (POLI, 2012, p.20). Com relação ao contato com a língua francesa, vale ressaltar que ele teve uma professora em Salvador que, assim como Gina, daria a ele algumas noções do idioma. Ele nos conta que:

[...] mais tarde, quando aprendi francês e outras línguas fluentemente e sem sotaque, preferia propositadamente manter um certo sotaque e entonações que lembrassem minhas origens brasileiras em todas as línguas que falava para que ao me ouvirem me compreendessem perfeitamente mas soubessem que não era europeu nativo, mas provavelmente de algum lugar da América Latina e que me orgulhava desta origem. (POLI, 2012, p. 25)

Em 1984, com a queima do Mercado Modelo em Salvador (onde estavam os maiores clientes da família), os Poli se preparam novamente para mudar; neste caso, teve que se separar tendo em vista as dificuldades financeiras pelas quais passava. A partir de então, a mãe de Ivan passa assumir o comando da família ao abrir um comércio na Avenida Sete de Setembro, na praça da Piedade. Aqui, mais uma vez, a religiosidade aparece com toda força, assim como sua defesa pelas mulheres e pelas culturas africanas. Sua mãe oferece o seu comércio a Yansã, por ser filha desta Orixá. Ele afirma: 
Neste tempo, posso dizer que esta deusa foi responsável por nosso provento e a ela dedico o depoimento abaixo que escrevi em meu livro “Antropologia dos Orixás”. [...] Neste período esta deusa esteve presente em minha mãe, deusa esta que via na maioria das mulheres negras e mestiças que não raro eram chefes de família assim como minha mãe. ... Yansã domou a dor do meu vazio de não poder estudar, domou a dor da desonra de nosso povo humilhado pelas desigualdades, a dor da tristeza das mulheres injustiçadas que somente querem lutar para criar seus filhos, e a dor pobreza por termos perdido tudo o que tínhamos ... Realmente não sei o que teria sido de nós se não. (POLI, 2012, p. 32)

Logo após a abertura deste empreendimento comercial, mais uma vez a família de Ivan se vê desestabilizada economicamente com os sucessivos planos da economia brasileira e decide retornar a São Paulo, para morar na casa de uma tia. Sair de Salvador foi sentido como uma perda para Ivan. E foi nessa época que ele começou a ter contato sistemático com o candomblé e descobriu que é filho de Oxum.

Ivan começa a perceber que mudar de lugar indicava mudar de identidade: “No Nordeste era o Paulista e em São Paulo, era o baiano, porém meus colegas me respeitavam por ser um bom aluno e ser considerado pela diretora como o melhor aluno da escola" (POLI, 2012, p. 24). No cerne deste relato autobiográfico, notamos que nosso sistema social encontra-se integralmente em cada um dos atos, sonhos, delírios, obras, comportamentos de Ivan, o que avaliza a interpretação de que a história desse sistema está contida por inteiro na história da nossa vida individual. (FERRAROTTI, 1998)

No Ensino Médio, optou por fazer o técnico em eletrotécnica no período noturno. Em 1991, entra para o Exército. Nesta época, Ivan começa a se interessar pelo estudo de línguas:

Começo a frequentar com amigos da Federal o Centro Cultural São Paulo e todos os sábados das 8 da manhã às 6 da tarde passávamos em um grupo de estudos de línguas de umas doze pessoas estudando espanhol, alemão, francês, inglês e italiano , contratávamos professores destas línguas que se alternavam em nosso grupo e no tempo restante monopolizávamos as cabines de cursos de línguas 
e os métodos da biblioteca. Os que estudávamos e os outros como holandês, sueco, árabe, chinês, e todas as línguas disponíveis aí. Com meu primeiro salário de monitor me inscrevi em uma instituição para conseguir endereços de pen-pals interessados em se corresponder comigo em outras línguas (sobretudo francês, inglês, alemão e espanhol. (POLI, 2012, p. 34)

Apesar da vida movimentada de Ivan e de seus contatos com outros países, a relação que dá um tom especial ao seu percurso é aquela estabelecida com Vaishali:

Porém acho que a pessoa mais importante no contexto de minha vida que conheci nesta época foi Vaishali, Uma indiana de que me introduziu aos Vedas e à cultura Vedantina. Nos correspondíamos pelo menos duas vezes por mês e trocávamos impressões sobre nossas culturas. Eu falando dos deuses afro-brasileiros e ela falando dos deuses indianos e da Fundação Ramakrishna. Fui introduzido nesta época a um dos filósofos mais importantes de minha vida, Vivekananda. Vaishali era uma espécie de esposa de alma que me casei pelo correio do destino. Certo dia para selar nosso relacionamento ela me envia um grão de arroz com meu nome escrito nele por ela mesma para dizer que minha amizade era como o arroz que a alimentava e eu a envio minha primeira guia de Oxum para que guardasse próximo a suas deusas das águas para que Oxum a protegesse. (POLI, 2012, p. 36)

A partir de 1993, Ivan começa a trabalhar para empresas multinacionais e internacionais, mais especificamente nas áreas de aviação e turismo, na Air France. Visitou, por isso, 22 países em cinco continentes, e em cada um deles conheceu algumas de suas instituições religiosas e educacionais. Foi neste contexto que teve oportunidade de ir até a casa de Vaishali em Hyderabad:

[...] e ela ao abrir a porta de camisola se surpreende ao me ver e não acredita. Vamos até seu serviço e ela pede dispensa para me levar para todos os lados de Hyderabad. Ela me leva até a fundação 
Ramakrishna e conheço o centro de línguas da fundação onde a metodologia de ensino me chama a atenção por reafirmar a identidade indiana no ensino de outras culturas, enriquecendo o universo simbólico dos alunos a partir de seus próprios referenciais ao invés de eclipsar a cultura local para ressaltar a cultura européia das línguas que eram ensinadas. O trabalho daqueles educadores se centrava no enriquecimento do universo simbólico daqueles aprendizes através da valorização de sua cultura, identidade e tradições para que dessa forma , com a ampliação e valorização de seu próprio universo simbólico, pudessem se apropriar de outros padrões cultos de linguagens. O caminho para esta apropriação de novas linguagens passava pela valorização destas culturas originais e não a desvalorização de suas próprias identidade e cultura indianas (no caso, telugu) em detrimento de uma identidade britânica, francesa, germânica, hispânica como na maioria das metodologias de ensino de línguas que observamos em escolas de línguas no Brasil e Ocidente. (POLI, 2012, p. 42)

Neste período, conhece o Vedanta e sua filosofia. Lê os principais Upanishads e aqui encontra o tema da sua iniciação científica realizada na USP entre 2007 e 2009.

Nestas suas viagens, teve a oportunidade de, no ano de 1997, assistir aulas de Pierre Bourdieu no College de France, fato marcante que promoverá sua formação acadêmica a partir da perspectiva teórica daquele autor.

Ivan continua seu caminho pelo mundo, saboreando cada momento: Egito, Espanha e Itália. Neste país, acontece um fato muito interessante, que ele relata dessa maneira:

Em Roma, sou confundido com um cigano egípcio no aeroporto de Roma e por isso quase sou preso por dois Carabinieri. Só não me detiveram por que lhes falei em italiano e reconheceram um sobrenome italiano em meu passaporte que por ser verde acreditavam ser da Líbia. o que mais os intrigara foi o fato de apesar de ter sobrenome italiano e falar italiano fluentemente não tinha passaporte italiano. Como se ser da Comunidade Européia fosse 
uma condição que elevasse o valor moral e ético das pessoas. Se não fosse por Vaishali, neste momento teria desistido de buscar minha dupla nacionalidade. (POLI, 2012, p. 43)

Aqui, mais especificamente em Veneza, encontra documentos que falam do seu sobrenome, Poli.

Segundo diziam os documentos de Veneza, os Poli eram diversas famílias gregas ortodoxas que no século XII teriam vindo para a cidade fugidos das Cruzadas de Bizâncio e contratados pelos senhores ricos da cidade para fazer os Mosaicos da Catedral de San Marco e posteriormente San Giorgio Maggiore e que em parte ( não meus ancestrais ) se tornaram uma família poderosa por fazerem embarcações na época da expansão comercial de Veneza no Mediterrâneo e por isso em Veneza há até mesmo o Castelo dos Poli, que nunca chegaram a participar na sucessão dos Dodges de Veneza pelo o que vi no Palazzo Ducale por serem originalmente bizantinos, sendo que famílias de origem não veneziana , como os judeus ou gregos por mais ricos pudessem ser jamais poderiam aspirar ao cargo de Dodges ou outros cargos na administração Veneziana.

Dizem que o nome Poli vem do fato que ao chegarem em Veneza aquelas famílias gregas ao serem perguntadas em italiano sobre o que poderiam fazer, respondiam, em grego, Poli (muito, muita coisa), pela versatilidade que a necessidade os obrigou a ter e daí todas elas ficaram se chamando os Poli, que na verdade eram antes de tudo artistas construtores de mosaicos. Disse ao saber destas origens que iria a Istambul, tão logo pudesse, tentar conhecer Santa Sofia e o patriarcado ecumênico de Fener, onde está o papa Ortodoxo, as origens primeiras dos povos que deram o nome que carrego por origem paterna. (POLI, 2012, p. 45)

Na medida em que Ivan não conseguiu achar a certidão de nascimento do seu bisavô ${ }^{4}$, não obteve legalmente a cidadania européia e, por isso, pede a sua noiva que espere um pouco. Ocorre o inesperado, que vai sacudir sua vida: 
A partir disso seus tios na India que tinham posses, aproveitam a chance e resolvem pagar seu dote para que casasse com um noivo indiano e os livrasse do estigma de terem uma sobrinha casada com um estrangeiro. Alguns meses depois recebo uma carta de despedida dizendo que não estava se casando forçada, mas que gostava de seu novo noivo com o convite de casamento. Fiquei abalado, mas compreendi. Por meu trabalho não pude ir a seu casamento em Hyderabad na época, mas prometi que em dois meses a visitaria assim como a toda sua família e voltaria a India. Estava já programando para ir à India e ao ligar para sua casa em Hyderabad, sua irmã atende e conversamos. Ao perguntar sobre Vaishali, sua irmã me diz que ela havia sido queimada viva em uma pira como diz a tradição pela família não ter tido dinheiro suficiente para o dote exigido na ultima hora do casamento ,para que assim o noivo ficasse livre para escolher outra mulher. Bem isso é tido como crime na India, contudo é uma prática que ainda ocorre sobretudo em pequenas cidades e no interior. (POLI, 2012, p. 47)

Ao melhorar, lembrou que Vaishali, na carta que lhe escrevera, pediu que não deixasse os seus estudos de Vedanta, dos Upanishads, de Swami Vivekananda e do Baghavad Gita. Neste mesmo ano, começou a estudar o Baghavad Gita em um grupo de estudos e traduziu os Upanishads do francês para o português. Mesmo tentando fazer sua vida avançar, a sensação de perda era imensa: "Contudo o sentimento de anulação, vazio e incapacidade de reagir era muito grande e não conseguia falar sobre o assunto com ninguém, nem meu médico ou minha mãe sabia o motivo de minha crise, atribuindo ao stress somente". (POLI, 2012, p. 35)

Apesar de continuar interessado em conhecer outros locais do mundo e assim o fazer, em 2004 Ivan decide reagir: retoma seus estudos no Brasil. Com 31 anos, sem ter terminado o ensino técnico, ingressa no curso de Pedagogia da Faculdade de Educação da Universidade de São Paulo. Ele relata que suas experiências na FEUSP, tendo em vista o seu interesse por outras culturas, muitas vezes não foram bem aceitas; tal como ao estudar o Alcorão e ser visto com o livro nos corredores da faculdade foi

[...] considerado por alguns professores e alunos da minha faculdade como simpatizante de terroristas fundamentalistas 
islâmicos, sem ao menos ser islâmico e no mundo muçulmano não ser nada além de um infiel. Em uma determinada aula um professor me critica severamente e defende que devemos defender nossas origens culturais européias e ocidentais em detrimento de qualquer outra cultura, como se elas já não fossem hegemônicas no meio acadêmico brasileiro e precisassem de defesa. (POLI, 2012, p. 50)

Tendo em vista este seu passado e a atual vida estudantil na FEUSP, resolve começar um projeto, na Bahia, contra exploração sexual de crianças e mulheres, apoiado por uma organização não-governamental européia que com a qual havia feito contato em sua última viagem à Europa. Aqui, mais uma vez, temos uma tomada de decisão:

No mesmo momento em que decido isso, pois também estava insatisfeito no serviço com a desonestidade e falta de ética dos métodos de meus chefes para me tirar de circulação por contrariar meus interesses faz deixar meu serviço de 9 anos em nome de meu ideal. Porém devido a revolta que passei com a deslealdade de meus antigos chefes escrevi um texto, que talvez tenha sido a coisa mais idiota que tenha escrito até hoje e que define tudo o que passei neste período e ironiza suas personalidades que fazem tudo por poder e pela fama efêmera dos noticiários que são esquecidos no dia seguinte.

Por causa deste texto até hoje sou perseguido e difamado no mercado e prejudicado de toda forma que podem me prejudicar os poderosos do meio empresarial em que trabalhei. Por isso transcrevo abaixo neste relato.... Estava tão irado quando escrevi que nem corrigi meu francês, mas todos entenderam e na hora serviu para seus propósitos e descreve bem de maneira irônica o que passei nas mãos destas pessoas desleais entre outras coisas. Expressa bem toda a revolta pelas injustiças que passei naquele momento. (POLI, 2012, p. 52)

Segundo Ivan, este texto - que pode ser conhecido na íntegra no livro que resulta deste relato -, gerou retaliações de seus superiores e 
Como resultado da raiva dos meus chefes por este texto, chegaram mesmo a fazer uma doação para a ONG que trabalhava para que não me abrigasse mais a mim nem meus projetos. E o padrinho político de um tradicional partido de direita ligado a uma tradicional família da Bahia e a líder da ONG que me abrigou no Brasil disse que meu projeto (por combater na raiz o problema da exploração sexual infantil) espantava turistas e que minha moral e conduta familiar não eram apropriadas para trabalhar com eles (Lógico, depois da gorda contribuição que receberam da fundação da empresa eu trabalhava através de uma ONG européia a qual se associaram. (POLI, 2012, p. 56)

Nessa situação, aliada à falta de trabalho e à recusa que recebeu de um empregador na França, Ivan volta decepcionado ao Brasil. Com o apoio de alguns professores da USP, reingressa na universidade com a esperança de cumprir seu juramento para Oxum: dedicar a vida contra a discriminação racial, de gênero e religiosa.

Notamos claramente, neste texto, a finalidade de uma epistemologia da prática profissional do pesquisador, pois temos aqui revelados seus saberes: a integração, a incorporação, a transformação deles, o que nos dá a possibilidade de compreender a natureza desses saberes, assim como o papel que desempenham tanto no processo de trabalho do pesquisador-docente quanto em relação à identidade profissional dos professores. (Cf. TARDIF, 2002)

Desta forma, no ano de 2007, ele abraça a causa da Lei 10.639/03 que trata do ensino das culturas africanas e afro-brasileiras no Brasil, e ingressa no mestrado da FEUSP. Em 2010, começa a escrever seu primeiro livro: "Antropologia dos Orixás". Assim, aproximamo-nos dos dias de hoje, Ivan faz a seguinte reflexão sobre quem ele é:

Na minha estada na Europa percebi que não era branco como achava até então, mas sim mestiço por ser tratado lá sempre como o outro e me orgulho disso pois conhecendo o que o movimento eugenista e as coisas bárbaras que alguns povos da humanidade fizeram em nome deste pensamento eugenista teria poucos motivos para me orgulhar em ser branco e muito mais para me envergo- 
nhar. De qualquer forma, acho incrível que nossa academia veja maravilhas em nossa mestiçagem através de célebres personagens de nossa história. Contudo é incrível como os títulos acadêmicos no Brasil embranquecem as pessoas pois quando se referem a estes mestiços o fazem de maneira tão europeizada e como não lhes dissesse respeito a suas próprias condições de mestiços em maioria. Realmente dificilmente nos liberaremos de nossa dependência intelectual e nosso pensamento acadêmico terá o real vulto de uma nação que quer tomar espaço na comunidade internacional enquanto não reconhecermos nossas origens integrais e fizermos com que estas origens saiam da invisibilidade e assumam seu lugar em nossa academia [...] Por estes fatores cheguei a conclusão que a imersão na invisibilidade de parte de nosso universo cultural em nosso meio acadêmico e a discriminação e os preconceitos barram nosso desenvolvimento como Nação que só ocorrerá quando afirmarmos integralmente nossa identidade coletiva com todas as cores e matizes que lhe são próprias o que nos tornará uma sociedade mais igualitária. (POLI, 2012, p. 56)

Consideramos que esta autobiografia, além de contribuir com a formação do professor universitário, oferece também espaço para a formação do pesquisador em início de carreira e, consequentemente, apresenta desafios à própria autobiografia enquanto metodologia de investigação.

\section{Parte III: Desafios para a formação de novos pesquisadores}

Pudemos perceber, por meio do relato de Ivan, que a autobiografia educativa, desenvolvida na disciplina da FEUSP, concede uma atenção muito particular e um grande respeito pelos processos biográficos das pessoas que se formam. Nisso reside uma das principais qualidades a distinguir essa metodologia da maior parte das que se utilizam na investigação em ciência sociais (NÓVOA; FINGER, 2010, p. 23). Dito de outro modo, tal momento formador é claro quanto aos seus propósitos de formação do professor, sem deixar de oferecer espaço para a formação do pesquisador. Nas palavras de Ivan Poli (2012, p. 45): 
O que mais se ressaltou no grupo em geral foi que em sua maioria os objetivos e projetos exeqüíveis dos participantes estavam relacionados ao próprio processo de pós-graduação. Comigo não foi diferente e percebi quer a experiência que me levou ao meu tema de pós- graduação estava relacionada com meu percurso de vida.

Em suma, concordamos com Nóvoa de que a preocupação com a pessoa do professor-pesquisador em início de carreira é central na reflexão educacional e pedagógica. Temos, portanto, a consciência de que a formação de Ivan depende do seu trabalho e que, mais importante do que isso, é "que todo conhecimento é autoconhecimento e que toda formação é autoformação" (NÓVOA, 1998, p.24). A construção de referenciais teóricos a partir de Bourdieu também pode ser observada neste percurso de vida e, finalmente, todos os temas de sua pesquisa saem da sua experiência pessoal.

Desse modo, o desafio está posto: o pesquisador que utiliza a autobiografia como metodologia de pesquisa na sua investigação precisa passar, ele mesmo, pela vivência da autobiografia? E ainda, passar pela autobiografia promove a realização de pesquisas autobiográficas? Até que ponto esses pólos (fazer sua autobiografia e pesquisar pela autobiografia) dialogam?

Do nosso ponto de vista, é não apenas desejável, mas necessário, o oferecimento desta disciplina na FEUSP para os pesquisadores, sobretudo quando estes estão interessados em utilizar a autobiografia educativa em sua pesquisa de campo com professores. Dizemos isto por entender que o pesquisador, enquanto tal, também se forma como professor que é ou virá a ser, e como investigador, inclusive, pois esta prática promove o diálogo enquanto enunciados advindos de sujeitos em posições diferentes, e "não apenas como a comunicação em voz alta, de pessoas colocadas face a face, mas toda comunicação verbal, de qualquer tipo que seja” (BAKHTIN, 1979, p.109). Tal postura,

[...] por um lado ela permite identificar as características seguidas pelos formadores (uma categoria profissional que ainda não está institucionalizada) na sua própria dinâmica de formação e na aquisição de competências técnicas específicas à função que desempenham; por outro lado, ela facilita a definição dos saberes e das formações mais necessárias para o exercício da função de formador (NÓVOA; FINGER, 2010, p. 26). 
O caso de Ivan, aqui apresentado, reitera a afirmação de Carino (1999) de que biografar é descrever a trajetória única de um ser único, original e irrepetível; é traçarlhe a identidade refletida em atos e palavras. E ainda, a biografia aqui vista deixa claro que são exaltados, criticados, demolidos, negados, santificados e dessacralizados pessoas, imagens, referenciais, ideais no âmbito da formação de pesquisadores.

Ivan busca a sua identidade: Poli, como seu nome. Busca a resposta para a eterna questão humana do "Quem sou eu?", "de maneira a situar a si-mesmo e aos outros pelo viés de um sistema de referências numa coletividade com seus laços simbólicos ou concretos e seu "ser-no-mundo" (JOSSO, 2007, p. 425), inclusive acadêmico, da investigação.

Deste modo, podemos transferir para o âmbito da formação de pesquisadores, aquilo que Shön (1995) propõe para a formação do professor: uma epistemologia da prática, ou seja, a valorização da prática investigativa como momento de construção do conhecimento de si mesmo e, futuramente, dos sujeitos de sua pesquisa, pela reflexão, análise e problematização desta. Lembremos que Alarcão (1996), ao descrever uma proposta de supervisão no modelo reflexivo de formação de professores - e aqui nós dizemos: de formação de investigadores -, isto é, a reflexão, no relato autobiográfico, dos temas e das metodologias de pesquisa empregados, dos autores escolhidos para o quadro teórico e assim sucessivamente. Dito de outro modo, agora nas palavras de Josso (2007, p. 414):

Os lugares educativos, sejam eles orientados para uma perspectiva de desenvolvimento pessoal, cultural, de desenvolvimento de competências sociais ou ainda para uma perspectiva de formação profissional, acolhem pessoas cujas expectativas e motivações a respeito da formação e dos diplomas referem-se, tanto a problemáticas de posicionamento na sua vida quotidiana e na sua ação em nossas sociedades em plena mutação, como às questões e problemáticas.

Assim, do nosso ponto de vista, a possibilidade de produzir um relato autobiográfico no âmbito do programa de pós-graduação da FEUSP promove a possibilidade de tomada de consciência dos processos pelos quais os adultos se formam, neste caso, os jovens pesquisadores.

Nessa perspectiva, concordamos com Finger (1988) quando enfatiza que este método se justifica como tal, pois valoriza a compreensão que se desenrola no 
interior da pessoa do pesquisador, sobretudo em relação a vivências e experiências que tiveram lugar no decurso da sua história de vida. Vale ressaltar, como afirma Bolívar (2002), que a produção do relato autobiográfico orienta o jovem pesquisador no seu desenvolvimento profissional, constituindo fonte de compreensão das respostas e ações no contexto da própria pesquisa que este realiza no stricto sensu.

Finalmente, consideramos que, nos marcos desta disciplina, o aluno se prepara para utilizar a autobiografia na sua própria pesquisa deparando-se com

[. . . ] mouvances d'un défi bio-éthique tendu entre le paradigme de la commande et du contrôle et celui de l'autonomisation. Il est incertain et irrésolu. Mais dans ces luttes de pouvoirs pour l'accès aux savoirs sur la vie, sa maîtrise représente un moyen vital stratégique pour construire du sens et produire la vie. (PINEAU, 2002, p. 122) ${ }^{5}$

\section{Notas}

1 O conteúdo e os objetivos da disciplina aqui apresentados foram extraídos do Portal CAPES.

2 Uma versão expandida deste relato resultou em livro, publicado em 2012, com o mesmo nome, com 182 páginas.

3 Momento- charneira é considerado pelos estudiosos da autobiografia como passagens da vida das pessoas em que estas tomam decisões importantes que alteram os seus percursos pessoais.

4 Tal documento foi tirado por seus pais quando todos chegaram ao Brasil, para que o seu bisavô não fosse prejudicado por ser italiano no processo de imigração da família para a América.

5 Tradução livre dos autores: "[ . . . ] movimentos de um desafio bioético que se estendem e o paradigma de comando e do controle e o do processo de autonomia. É incerto e irresoluto. Mas nessas lutas de poder pelo acesso ao conhecimento aos saberes da vida, o seu controle representa um meio vital estratégicco para construir sentido e produzir a vida".

\section{Referências}

ALARCÃO, I. Professores reflexivos em uma escola reflexiva. São Paulo: Cortez, 2007.

BAKHTIN, M. Estética da criação verbal. São Paulo, SP: Martins Fontes, 1997. 
BOLIVAR, A. (Dir.). Profissão professor: o itinerário profissional e a construção da escola. Bauru, SP: EDUSC, 2002.

CAPES. Memória da pós-graduação. Sistema de avaliação. In:http://wwwl.capes.gov.br/ estudos/dados/1998/33002010/038/1998_038_33002010001P6_Disc_Ofe.pdf. Acesado em 10 de junho de 2012.

CARINI, J. A biografia e sua instrumentalidade educativa. Educação \& Sociedade, Campinas, ano XX, no 67, Agosto/99.

DELORY-MOMBERGER, C. Biografia e educação: figuras do indivíduo-projeto. Natal: EDUFRN; São Paulo: Paulus, 2008.

FERRAROTTI, F. Sobre a autonomia do método biográfico. In: Nóvoa, António; Finger, Mathias. O método (auto)biográfico e a formação. Lisboa: MS/DRHS/CFAP, 1988.

FERRAROTTI, Franco. Sobre a autonomia do método biográfico. In: NÓVOA, António; FINGER, Matthias (Org.). O método (auto)biográfico e a formação. Natal, RN: EDUFRN; São Paulo: Paulus, 2010

FINGER, M. As implicações sócio-epistemológicas do método biográfico. In: NÓVOA, FINGER, M. (Org.). O método (auto)biográfico e a formação. Lisboa: MS/DRHS/CFAP,1988.

JOSSO, M. C. A transformação de si a partir da narração de histórias de vida. Educação. Porto Alegre/RS, ano XXX, n. 3 (63), p. 413-438, set./dez. 2007.

MACIEL, S. D. A literatura e os gêneros confessionais. In: Antonio Rodrigues Belon \& Sheila Dias Maciel (Orgs.). Em diálogo: estudos literários e linguísticos (pp. 75-91). Campo grande, MS: Ed. UFMS, 2004.

NÓVOA, A. (org.). Vida de professores. Porto: Porto, 1995. Profissão professor. Porto: Porto, 1995.

PINEAU, G. Les histoires de vie en formation: genèse d'un courant de recherche-actionformation existentielle, 2002.In :http://www.scielo.br/pdf/ep/v32n2/fr_a09v32n2.pdf. Acessado em 7 jun. 2012.

POLI, I. da S. Índia, Vedanta e educação, a experiência Ramakrishna. São Paulo: Biblioteca 24 horas, 2012.

(mimeo)

. O Filho das águas pelas Índias e Orientes. Relato autobiográfico. São Paulo, 2011.

SCHÖN, D. A. Formar professores como profissionais reflexivos. In: NÓVOA, A. (Coord.). Os professores e sua formação. Lisboa: Dom Quixote, 1992.

TARDIF, M. Saberes docentes e formação profissional. Trad. Francisco Pereira. Petrópolis: Vozes, 2002.

recebido em 19 set. 2012 / aprovado em 20 nov. 2012

Para referenciar este texto:

SILVA, N.; POLI, I. S. A autobiografia educativa na FEUSP: desafios para a formação de pesquisadores em início de carreira. Dialogia, São Paulo, n. 16, p. 47-64, 2012. 